\title{
Distance learning: Artistic disciplines in expectations and results
}

\author{
I.A. Lvova ${ }^{1}$, and N.A. Bakhlova ${ }^{2 *}$ \\ ${ }^{1}$ Moscow State Regional University, Mytischi, Russia \\ ${ }^{2}$ Kaluga Federal University, Kaluga, Russia
}

\begin{abstract}
The long period of distance learning in higher education has set difficult tasks for teachers. The article analyzes the course and results of an experiment that was conducted at the Department of Folk Art Crafts of the Moscow State Regional University in 2020. The experiment involved three groups of students in two fields of study: 54.03.01 Design, specialty Costume Design (CD) and 54.03.02 Decorative and Applied Arts and Crafts (DAAC). Students independently identified problems that could arise during distance learning. These are objective factors, such as: insufficient mastering of skills of working with materials and tools, the inability to correct errors and shortcomings immediately, etc.; and subjective factors: psychological problems, deterioration of health indicators, etc. The authors of the article followed the changes in the problems of teaching and made analytical conclusions about how the students' attitude to the process of remote learning changed. Despite the positive dynamics in students' perception of online communication with teachers, some of the problems remain unsolvable. For example, the main problem in teaching creative disciplines, in our opinion, was the lack of direct contact between the master and the student, when the skill of artistic work is transferred "from hand to hand". The authors conclude that the teaching of creative disciplines cannot be completely taken online.
\end{abstract}

\section{A problem statement}

Distance learning is not a new phenomenon for Russian education, but the spring of 2020 has made adjustments to the perception of this concept. From a vague perspective for many, it instantly turned into everyday realities, for almost all teachers and tutors of the Russian Federation. Such an instant transformation required maximum effort and patience from all representatives of the educational community. We would like to share our comments on the issue of working in a remote format for the last six months in creative areas of training.

The modern interpretation of distance learning states that it is training based on the spatial separation of teachers and trainees, and their interactive interaction with the use of modern information and telecommunication technologies.

\footnotetext{
*Corresponding author: prof-ped.gpa@mail.ru
} 
Today, in general, distance learning should be considered a natural result of the adaptation of education to modern conditions, and it must be said that the COVID-19 pandemic has only seriously spurred the course of this process. By "modern conditions" we mean a sufficient level of development of information technologies that allow us to build the learning process among participants in interactive communication, as well as a serious restructuring that takes place within the educational process and is aimed at creating conditions for the implementation of individualized learning [1]. And no matter how we talk about the role and possibilities of traditional learning, the new information and communication society dictates its own. So, according to UNESCO forecasts, in the near future, the share of classroom time for students will be no more than $30-40 \%$ of the total academic load, $40 \%$ will be accounted for by distance learning, and the rest of the time will be spent on self-education [2].

The current state of distance learning is such that practical developments are still seriously ahead of the development of its theoretical foundations. The most detailed research on this issue was conducted abroad. It is enough to mention the names of such researchers as D.J. Keegan, J.S. Daniel, B. Holmberg, M.G. Moore, G. Kersley, O. Peters, D. Sewart, etc [3-8]. Each of these authors offers their own author's concept of the development and structure of the essential characteristics of distance learning. But with all the variety of suggested approaches, it is possible to distinguish a number of common elements that are indicated in most concepts: the geographical distance between students and teachers in the learning process; a new type of educational communication due to the "separation of teaching and learning processes in time and space"; the study of the essential characteristics of distance learning [9].

Russian teachers also did not stay away from this problem, and in the post-Soviet area, quite extensive research is also being conducted on the introduction and consolidation of distance learning in the system of modern education. The most detailed concept of "distance learning" is covered in the works of Russian researchers E.S. Polat, A.A. Andreev, V.I. Ovsyannikov, M.Y. Bukharkina, V.I. Soldatkin, T.M. Sklyarenko, and others [10-12, 13-14].

According to E.S. Polat, distance learning should be considered as a new form of education, in which information and communication technologies are the means of implementing pedagogical tasks, tasks of training, education, and development. The conceptual apparatus of distance learning, according to E.S. Polat, includes such a concept as "pedagogical technologies of distance learning", which are implemented through specific means of Internet technologies [10-12].

In distance learning, as in any other form of education, a certain structure is distinguished: the goals determined by the social order for all forms of education; the content, also largely determined by the existing programs for a particular type of educational institution, methods, organizational forms, and means of training. According to A.A. Andreev and V.I. Soldatkin, it is possible to realize the goals of distance learning only if a number of conditions are met: the availability of the necessary material and technical base; granting the teacher the right to choose the organizational side of training. When constructing the educational process of distance learning, they include successively alternating periods of contact and non-contact time $[13,14]$. Depending on the degree of participation of the teacher in the learning process (contact and non-contact time) and the synchronicity of the student's employment, a classification is proposed that distinguishes three types of distance learning: synchronous, asynchronous and hybrid (mixed). The synchronous type of distance learning involves the use of online classes, which are conducted by the teacher according to an approved schedule. In the asynchronous type, students study the material and take various types of tasks (tests, essays, etc.) by the set deadline, while the participation of teachers in this process is minimized. Mixed training is 
designed so that part of the teacher is conducted online, in real time, and part of the classes are taught when it is convenient for them. Each type has its own nuances, advantages and disadvantages [2]. As noted by T.M. Sklyarenko, working in a remote format in real time (seminars, virtual conferences, round tables, etc.) contributes to the development of strong interpersonal contacts "student - teacher", "student - student", as well as the full functioning of the "live" educational environment, which is based on pedagogical principles [9].

\subsection{The objective of the work}

In our small study, the key issue is to identify the features of the construction of the processes of art education within the total distance. From our point of view, not enough works devoted to this problem are published yet. Let's focus on some publications. Thus, Lykova E.S. and Sukharev A.I. see distance learning as an independent line in art education, including digital technologies and traditional types of fine arts [15]. They identify a number of subjective problems, including, first of all, the level of readiness of teachers to use digital technologies in art education. The force majeure conditions of the total distance required art teachers not only to master the work with digital education software in the shortest possible time, but also to simulate the author's method of conducting classes. The researchers propose to solve these problems by introducing mandatory courses on digital literacy into the system of training teachers of artistic orientation [15].

The objective problem of distance learning in art disciplines Lykova E.S. and Sukharev A.I. called the inability of students to work in specially equipped workshops and, as a result, the occurrence of difficulties in students associated with the implementation of the training tasks [15]. In addition, the objective problems of distance learning can also include the need for non-verbal communication between the teacher and the student at the stage of mastering various artistic techniques of work: "setting the hand", working with materials, emotional contact, etc. [16].

\section{Results of the research}

The experiment began in March 2020, when all educational institutions switched to a distance learning format. This compulsory measure forced higher school teachers to look for new methods and means, not only for the teaching process itself, but also in order not to maintain the level of training, in order to create such conditions that would ensure the assimilation of competencies.

The Department of Folk Art Crafts of the Moscow State Regional University provides education in two areas of training: 54.03.01 Design, Costume Design profile and 54.03.02 Decorative and Applied Arts and Crafts. In the experiment at the first stage, i.e. in the second semester of the 2019-20 academic year (March - June), three groups of students participated:

CD-18, with the discipline of the Basics of production skills;

CD-17, with the discipline Specialization (Modern costume).

At the second stage, in the first semester of the 2020-21 academic year (OctoberDecember), three groups also took part in the experiment, two of them the same:

DAAC-20, with the discipline of the Basics of production skills;

CD-18, with discipline Specialization (Modern suit);

as well as the group of CD-19 with the discipline of the Basics of production skills. 
All disciplines, except the Basics of the theory and Methodology of Design in the decorative and applied arts, are purely practical in nature and consist of laboratory work. In the course of the Basics there are lectures and practical classes.

In this study, we do not aim at a detailed analysis of the learning stages themselves, we tried to analyze the expectations and results that are the accompanying factors of total distance work with students.

The total amount of students who participated in the experiment was 28 . At the beginning of the experiment, a survey was conducted among the students. Its purpose was to identify the expected disadvantages and advantages of distance learning, to determine whether there is a fear of insufficient assimilation of the material, mistakes in the performance of tasks, etc.

Table 1 shows the negative expectations of students, and, as revealed by the analysis of the survey results, the difference in expectations between the first, second and third years was insignificant, so we did not divide the students according to the years of study.

Table 1. Results of the survey of students at the beginning of the first stage of the experiment.

\begin{tabular}{|l|l|l|l|}
\hline \multicolumn{1}{|c|}{ Negative expectations } & $\begin{array}{c}\text { Number of } \\
\text { students }\end{array}$ & Percentages \\
\hline 1 & $\begin{array}{l}\text { Insufficient acquisition of skills in working with } \\
\text { materials and tools. }\end{array}$ & 22 & 78.5 \\
\hline 2 & $\begin{array}{l}\text { The impossibility to immediately correct errors and } \\
\text { defects. }\end{array}$ & 20 & 71.4 \\
\hline 3 & Lack of an atmosphere of cooperation. mutual assistance. & 18 & 64.2 \\
\hline 4 & Possible delay in completing tasks. & 15 & 53.5 \\
\hline 5 & Problems with computer software. & 3 & 10.7 \\
\hline
\end{tabular}

Thus, at the beginning of the experiment, the students identified five possible problems, two of which are of a personal nature. In paragraph 4, there is a fairly high self-criticism of students: more than half suggest delaying the completion of tasks without full-time control by the teacher due to procrastination. However, in general, the students did not predict any psychological or other health problems.

At the same time, the supposed advantages of working in a remote format were also identified, these are: 1 , No time spent on the road and 2. The distribution of time and effort to complete tasks at your own. In the subsequent work, the factors of positive expectations practically did not change, so we do not put them in a separate table.

How were the classes conducted during the first stage of self-isolation? Let's consider this question. A detailed analysis of the first-year group's training in the direction of Decorative and applied Arts and folk Crafts is contained in the publication of Ilyushina O.V. and Lvova I.A. [17]. As for the disciplines of a purely practical orientation, for which the Curriculum provides only laboratory work, the ZOOM, WhatsApp, Skype platforms were used for their remote conduct; teachers made presentations on the topics of classes, recorded master classes, which were then uploaded to cloud storage or to the YouTube video hosting service and attached to the EEE (electronic educational environment). There was also a Forum for communication, where students laid out the intermediate stages of, asked questions, where there was a constant productive dialogue. In addition, students were recommended literature from the electronic library of the Moscow State University, from library systems that have a contract with our university: ZNANIUM.COM, IPRbooks. Teachers found additional resources on the Internet to consolidate their knowledge and skills. Links to sources for learning additional material were embedded in the EEE before each lesson. The system of tasks in the EEE allowed to set points, which were then added up to the intermediate certification. In general, the whole system is built in such a way that it was easy to teach and control students, especially given the regular dialogue. And the 
results were not affected by some confusion of the initial period of the distance, when both teachers and students were getting used to using the means for remote communication.

Table 2 shows the results of the student survey at the end of the first stage. We observe significant changes in the positions of the expected negative results. And the positions themselves have become much more numerous.

Table 2. Results of the survey of students at the end of the first stage of the experiment.

\begin{tabular}{|l|l|l|l|}
\hline \multicolumn{1}{|c|}{ Negative expectations } & $\begin{array}{c}\text { Number of } \\
\text { students }\end{array}$ & Percentages \\
\hline 1 & $\begin{array}{l}\text { Insufficient acquisition of skills in working with } \\
\text { materials and tools. }\end{array}$ & 6 & 21.4 \\
\hline 2 & $\begin{array}{l}\text { The impossibility to immediately correct errors and } \\
\text { defects. }\end{array}$ & 8 & 28.5 \\
\hline 3 & Lack of an atmosphere of cooperation. mutual assistance. & 13 & 46.4 \\
\hline 4 & Possible delay in completing tasks. & 5 & 18 \\
\hline 5 & Problems with computer software. & 6 & 21.4 \\
\hline 6 & Non-acquisition of ultimate material processing skills. & 14 & 50 \\
\hline 7 & Psychological problems. & 16 & 57 \\
\hline 8 & Deterioration of health condition. & 17 & 60.7 \\
\hline 9 & The need to spend time loading completed tasks. & 24 & 85.7 \\
\hline
\end{tabular}

We can see that the range of problems has expanded. Compared to Table 1, the expected negative factors that the students assumed at the beginning of the experiment decreased. However, a number of other problems were revealed, the arrival of which was not indicated at the beginning. Let's look at the indicators in Table 2 in more detail.

- Insufficient mastering of skills of working with materials and tools. Students, for the most part, were convinced that, in the presence of video communication with the teacher, preparation of training videos, presentations for each lesson, direct visual demonstration of working with materials and tools, the ability to view videos repeatedly-all this made it possible to master the techniques of work quite well.

- The inability to immediately correct errors and omissions. Yes, this point was quite important for many students. It is not always possible to correct and eliminate errors on an already completed task, often something had to be done again. But here we see an increase in the responsibility of students in relation to their own work. If you don't want to do it again, attend the remote lesson, watch and listen carefully, try hard, ask questions, and show the intermediate stages of the work via video link.

- Lack of an atmosphere of cooperation and mutual assistance. This factor was important for almost half of the respondents. Yes, we agree, when teaching creative disciplines, the moment of mutual participation in work, consultation, discussion - this can even be called one of the methodological techniques of a teacher. Social partnership and interaction between participants in the training process is an important aspect in the training of designers [18]. Probably, mutual discussion of the work during the video call was not enough. Unfortunately, it is very problematic to increase this indicator in distance learning.

- Possible delay in completing tasks. This item is significantly reduced in percentage terms compared to Table 1 . In the system of electronic educational environment (EEE), which is used in our university, it is provided to assign points for each completed task. If the deadline is not met, the points are reduced. This measure turned out to be very effective. Each student realized that, with high-quality performance of the task, losing points due to delaying deadlines is not very reasonable. However, the problem can be defined more broadly as the psychological problem of juvenile infantilism. Some ways to overcome it may have "axiological, student-based and activity-based approaches" [19]. 
- Problems with computer software. If the first survey was about the lack of equipment in the students' family that could provide remote communication, then the second survey revealed hitches with the speed or supply of the Internet, as well as the question of the price of the corresponding technical means. But in general, the students noted that these tasks are gradually being solved.

Next, we turn to the points in Table 2 that appeared in the course of the distance learning and were recorded by students at the end of the semester. This:

- Non-acquisition of ultimate material processing skills. Here we must say that exactly half of the respondents were students of the direction of Decorative and applied arts and folk crafts. These 14 people correctly noted this problem. Within the framework of the discipline "Fundamentals of theory and methodology of design in decorative and applied arts", this group received practical skills in artistic ceramics. Only at the beginning of the semester, during the first ten hours of practical classes, they did work directly with the material - clay. And then the work was done at home, using sculptural plasticine as the material. The students completed all the stages of working on the art product from sketches to a life-size model, but they did not have the opportunity to learn the skills of firing a ceramic product. Looking ahead, we can say that they received these skills at the beginning of the next semester (before the second stage of the distance), when, within the framework of the discipline "Fundamentals of Production Skills", classes were organized for them in the workshop, where they were able to make products in clay and make them fired.

- Psychological problems. The question of the impact of distance learning on the psychological state requires the study of doctors, psychologists, and other specialists. We will only note that the students expressed their emotions about the lack of normal live communication, about the increase in nervousness or apathy, about the lack of mutual understanding on the part of family members (who were also at a distance!) and these emotions were expressed very violently. We understand these problems. But we don't have a solution yet. We are an educational institution, not a psychotherapy service.

- Deterioration of health condition. Motor activity decreased, the load on the vision increased, the spine and lower limbs suffered from prolonged sitting at the computer. We must also take into account that not all students came to us to study initially healthy. Of course, we recommended getting up periodically and doing sports movements in video sessions. We even organized physical training sessions with the students. But, as we can see, the problem exists. it is indicated by a fairly high percentage,

- The need to spend time loading completed tasks. The EEE system cannot reflect the results of training without seeing them in the "completed tasks" section. Therefore, students, having made a series of sketches or a model of a sewing product, had to formalize the results of their work in the form of a presentation, or in another form, and upload them to the EEE. It is clear that after the work done, you want to switch to more pleasant activities, and not sit for another two hours, bringing the work in the desired form and uploading it to the EEE. But we think that this time spent is quite comparable to the time spent on the road to university and back, as it was with full-time training. We cannot know how negative long trips in public transport in such a metropolis as Moscow are, but we assume that this is less harmful than additional hours in front of a computer screen. I.e., one of the expected advantages (see above) in this case went into the negative, and therefore this indicator could be called zero, if not for the point about the Deterioration of health condition. And we leave this factor in the negative results section.

The test and examination session was also held in a remote format. For all the disciplines involved in the experiment, it was possible to obtain a fairly high level of competence development, with the correction that some of the practical art products were presented by students in the form of models. 
The second part of the experiment began in October 2020, when Russia again declared a self-isolation regime. It should be noted that some of the classes were held in full-time mode, and this was a good help in further work. The distance was expected, so during the classroom meetings, we tried to give students the maximum knowledge and skills, set clear tasks, and build algorithms. Therefore, the next survey of trainees about the possible negative consequences of online training did not show signs of panic. The experiment also involved 28 people. All groups were already familiar with the conditions of distance learning.

Table 3 shows the results of the students' survey in mid-October 2020, before the start of the second stage of the experiment. We suggested using all the same factors that were in Table 2 to see if the negative expectations changed compared to the first stage.

Table 3. Results of the survey of students at the beginning of the second stage of the experiment.

\begin{tabular}{|l|l|l|l|}
\hline \multicolumn{2}{|l|}{ Negative expectations } & $\begin{array}{l}\text { Number of } \\
\text { students }\end{array}$ & Percentages \\
\hline 1 & $\begin{array}{l}\text { Insufficient acquisition of skills in working with } \\
\text { materials and tools. }\end{array}$ & 4 & 14 \\
\hline 2 & $\begin{array}{l}\text { The impossibility to immediately correct errors and } \\
\text { defects. }\end{array}$ & 5 & 18 \\
\hline 3 & Lack of an atmosphere of cooperation. mutual assistance. & 14 & 50 \\
\hline 4 & Possible delay in completing tasks. & 2 & 7 \\
\hline 5 & Problems with computer software. & 4 & 14 \\
\hline 6 & Non-acquisition of ultimate material processing skills. & 8 & 28.5 \\
\hline 7 & Psychological problems. & 11 & 39 \\
\hline 8 & Deterioration of health condition. & 15 & 53.5 \\
\hline 9 & The need to spend time loading completed tasks. & 11 & 39 \\
\hline
\end{tabular}

A comparison of the data from Tables 2 and 3 shows that the level of negative expectations has significantly decreased. We believe that this is due to the fact that students were no longer afraid of online learning, they already had experience, and the level of consciousness in learning increased. It should be noted that the principle of activity and consciousness of learning in pedagogical science is considered as one of the most important [20]. Teachers also gained valuable experience in remote training in practical disciplines: methods were improved, labor and time spent on preparing for classes and on checking tasks were reduced. In general, the approach to conducting training has become more rational.

The last survey was conducted in the experimental groups at the end of December 2020, before the start of the mid-term assessments. Table 4 pleased us with its indicators:

Table 4. Results of the survey of students at the end of the second stage of the experiment.

\begin{tabular}{|l|l|l|l|}
\hline \multicolumn{2}{|c|}{ Negative expectations } & $\begin{array}{c}\text { Number of } \\
\text { students }\end{array}$ & Percentages \\
\hline 1 & $\begin{array}{l}\text { Insufficient acquisition of skills in working with materials and } \\
\text { tools. }\end{array}$ & 4 & 14 \\
\hline 2 & The impossibility to immediately correct errors and defects. & 4 & 14 \\
\hline 3 & Lack of an atmosphere of cooperation, mutual assistance. & 9 & 32 \\
\hline 4 & Possible delay in completing tasks. & 0 & 0 \\
\hline 5 & Problems with computer software. & 2 & 7 \\
\hline 6 & Non-acquisition of ultimate material processing skills. & 0 & 0 \\
\hline 7 & Psychological problems & 6 & 21.4 \\
\hline 8 & Deterioration of health condition & 12 & 42.8 \\
\hline 9 & The need to spend time loading completed tasks & 8 & 28.5 \\
\hline
\end{tabular}


In the first two points, four people were noted, these students were ill with COVID-19 in a rather severe form, but according to the result, as shown in point 4 , they have beaten the tasks quite successfully. Points 3 and 7 became less significant, because people in the family circle learned to interact more calmly, find mutual understanding, which reduced the need for communication in the student group (Figure 1).

\begin{tabular}{|c|c|c|c|c|c|c|c|c|c|c|c|c|c|c|c|c|c|c|c|c|c|c|c|c|c|c|c|}
\hline$\%$ & \multicolumn{27}{|c|}{$\begin{array}{l}\text { Diagram of changes in expected negative factors } \\
\text { during periods of full distance learning }\end{array}$} \\
\hline 100 & & & & & & & & & & & & & & & & & & & & & & & & & & & \\
\hline 90 & & & & & & & & & & & & & & & & & & & & & & & & & & & \\
\hline 80 & & & & & & & & & & & & & & & & & & & & & & & & & & & \\
\hline 70 & & & & & & & & & & & & & & & & & & & & & & & & & & & \\
\hline 60 & & & & & & & & & & & & & & & & & & & & 1 & 1 & & & & & & \\
\hline 50 & & & & & & & & 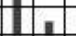 & & & & & & & & & & & & & & & & & & & \\
\hline 40 & & & & & & & & & & & & & & & & & & & & & 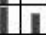 & 1 & & & & & 1 \\
\hline 30 & & 1 & & & & & & & & & & & & & & & & 11 & & & & & & & & & \\
\hline 20 & & & 11 & & & & 1 & & & & 1 & & & & & & & 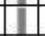 & & & & $\pi$ & 1 & 1 & & 4 & 11 \\
\hline 10 & & & & & & & & & & & & 1 & & & & 1 & & 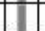 & & & & 1 & 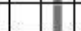 & & & $\pi$ & 11 \\
\hline$\frac{\text { Tab }}{\text { les }}$ & 1 & 2 & \begin{tabular}{l|l}
34 \\
\end{tabular} & 4 & 2 & 3 & 4 & $\begin{array}{lll}1 & 2 \\
\end{array}$ & \begin{tabular}{l|l}
3 & 4 \\
\end{tabular} & 4 & 2 & 3 & 4 & 1 & 23 & 4 & \begin{tabular}{ll|}
1 & 2 \\
\end{tabular} & 3 & 4 & & 23 & \begin{tabular}{ll|}
3 & 4 \\
\end{tabular} & $\begin{array}{lll}4 & 1 & 2\end{array}$ & 3 & \begin{tabular}{l|l}
4 & 1
\end{tabular} & 2 & 3 \\
\hline Fac & & 1 & & & & 2 & & 3 & 3 & & 4 & & & & 5 & & 6 & 6 & & & 7 & & 8 & 8 & & 9 & 9 \\
\hline
\end{tabular}

Fig. 1. Generalized results of student surveys during the experiment.

The issues of providing equipment (item 5) have also been practically resolved. Item 9 the students began to approach the distribution of time more rationally. To reduce the indicator of item 8 is not in our power and capabilities, but, nevertheless, it also gave a positive trend, Table 5 reflects the data in Tables 1-4 in the form of a diagram, giving a better visual representation of the results of the experiment. The bottom row is items 1-9 from the Tables, the second row from the bottom is the Table numbers. The evolution is reflected in the percentages.

\section{Conclusions}

Distance learning is currently undergoing a transformation from a "tool of mass education" to an "individualized form of obtaining the required knowledge and information", which allows us to think of distance learning as a promising form of education that accumulates the principles of the modern information society. But it must be remembered that there are areas of training that require direct and constant contact "teacher-student", the presence of well-equipped workshops and special materials. The teacher not only teaches, he also educates - by his example, by his attitude to the process of designing and executing a work of art. It is possible that we need to look for new forms, methods, tools, etc. within distance learning. But at the present stage, we firmly believe that the teaching of artistic and special disciplines of a practical nature in creative areas of training is possible only in the classroom format, and the transition to online training is required only in force majeure, which abounded in the past calendar year. We believe that distance learning in the areas of training that we have considered in this publication is only partially possible, no more than $10-15 \%$ of the total number of classroom hours.

\section{References}

1. G.V. Kuritsyna, Essential and meaningful characteristics of distance learning in higher education institutions, Bulletin of the Bryat state university, Education, Personality, Society, 2, 34-50 (2016) 
2. G.G. Karhanyan, Analysis of Distance Learning in Force Majeure Conditions, CrossCultural Studies: Education and Science, 5(2), 92-96 (2020)

3. D.J. Keegan, Distance Education, On Defining Distance Education, 1(1), 13-26 (1980)

4. J.S. Daniel, World Trends in Higher Distance Education and Opportunities for International Cooperation, In: UNESCO, Higher Level Distance Education, 17-42 (1987)

5. B. Holmberg, Theory and Practice of Distance Education, 200 (1989)

6. M.G. Moore, G, Kersley, Distance education, A system View, Belmont: Wadsworth Publishing Company, 219-222 (1996)

7. O. Peters, Distance teaching and industrial production: a comparative interpretation in outline, London Croom Helm, 120 (1983)

8. D. Sewart, Mass Higher Education: Where are We Going?, 240 (1987)

9. T.M. Sklyarenko, Foreign Concepts of Distance Education, The Education and science, 1(1), 106-116 (2013)

10. E.S. Polat, M.Yu. Bukharkina, M.V. Moiseeva, Theory and practice of distance learning, 130 (2004)

11. E.S. Polat, Organization of distance learning in the Russian Federation, Computer science and Education, 4 (2005)

12. E.S. Polat, A,E, Petrov, M,A, Tatarinova, etc,, Distance learning in a specialized school, 280 (2009)

13. A.A. Andreev, V,I, Soldatkin, Distance learning: essence, technology, organization, 150 (1999)

14. A.A. Andreev, V.I. Soldatkin, Applied Philosophy of Open Education: Pedagogical aspect, 160 (2002)

15. E.S. Lykova, A.I. Sukharev, Problems of art and pedagogical education in the conditions of distance learning, Modern science-intensive technologies, 12-2, 368-372 (2020)

16. A.S. Aleynikova, S.P. Roshchin, Modern problems of higher education, Theory and practice: Actual problems of creative education during the pandemic, On the integration of electronic educational resources in the educational environment of graphic design, Special Issue, 389-394 (2021)

17. O.V. Ilyushina, I.A. Lvova, From the experience of teaching the discipline "Fundamentals of theory and methodology of design in decorative and applied art" in remote format, Pedagogy of art, 1, 63-72 (2021)

18. E.N. Koveshnikova, P.A. Koveshnikov, N.A. Bakhlova, Social partnership in the process of training future designers, Education and society, 3(122), $70-77$ (2020)

19. A.V. Ivanov, S.P. Lomov, A.G. Akhtyan, Y.V. Shimanovskaya, L.G. Karandeeva, Research on the content of co-overcoming infantilizm of adolescents and youth as a psychologikal anl pedagogikal problem, Espacios, Sociacion de Profesionales y Tecnicos del CONICIT, 40(31), 1-10 (2019)

20. E.I. Sotnikova, D.V. Piliper, M.V. Galkina, Didactic principles of teaching folk decorative and applied art at school on the example of Zhostvskoy painting, Modern information technologies in education, science and industry, 120-123 (2020) 